\title{
Oral impacts on daily performances and its socio-demographic and clinical distribution: a cross-sectional study of adolescents living in Maasai population areas, Tanzania
}

Lutango D. Simangwa ${ }^{1^{*}}$ DD, Ann-Katrin Johansson ${ }^{1}$, Anders Johansson², Irene K. Minja ${ }^{3}$ and Anne N. Åstrøm ${ }^{4}$

\begin{abstract}
Background: In a global perspective, oral health among adolescents has improved during recent decades. However, oral problems still persist especially in many underprivileged societies. This study aimed to estimate the prevalence of oral impacts in adolescents and to identify important clinical- and socio-demographic covariates. In addition, this study compares Maasai and non-Maasai adolescents regarding any association of socio-demographic and clinical covariates with oral impacts on daily performances.

Methods: A total of 989 adolescents were invited from 23 randomly selected public primary schools in Monduli and Longido districts, Tanzania. All adolescents attending 6th grade classes were invited to participate. A total of 930 accepted and of those 24 were excluded, leaving 906 (91.6\%) participants for the study.

Results: A total of 143/906 (15.8\%) had at-least one oral impact on daily performances (OIDP > 0), 14.6\% among the Maasai and 20.5\% among the non-Maasai ethnic group. Cluster adjusted logistic regression revealed that: adolescents from Longido district $(\mathrm{OR}=0.4)$ and adolescents with good oral hygiene $(\mathrm{OR}=0.7)$ were less likely to report $\mathrm{OIDP}>0$ and; non Maasai $(\mathrm{OR}=1.6)$, those with least poor parents $(\mathrm{OR}=2.0)$, DMFT>0 $(\mathrm{OR}=3.1)$ and those with positive answers to questions regarding TMD pain, 2Q/TMD $>0(O R=3.9)$ were more likely to report OIDP $>0$. Stratified logistic regression by ethnicity revealed that, among the non-Maasais, older adolescents $(\mathrm{OR}=3.7,95 \% \mathrm{Cl}$ 1.1-12.8), those with DMFT $>0(O R=3.3(1.2-9.0)$ and $2 \mathrm{Q} / \mathrm{TMD}>0(\mathrm{OR}=9.0,95 \% \mathrm{Cl} 3.3-25.0)$ were more likely to report at least one OIDP. The corresponding figures among the Maasais were (OR=0.9, 95\% Cl 0.5-1.7), $(\mathrm{OR}=2.8$, $95 \% \mathrm{Cl} 1.4-5.5)$ and $(\mathrm{OR}=3.0,95 \% \mathrm{Cl} 1.7-5.2)$, respectively.

* Correspondence: Lutango.Simangwa@uib.no

'Department of Clinical Dentistry - Cariology, Faculty of Medicine, University of Bergen, Bergen, Norway

Full list of author information is available at the end of the article

(c) The Author(s). 2020 Open Access This article is licensed under a Creative Commons Attribution 4.0 International License, which permits use, sharing, adaptation, distribution and reproduction in any medium or format, as long as you give appropriate credit to the original author(s) and the source, provide a link to the Creative Commons licence, and indicate if changes were made. The images or other third party material in this article are included in the article's Creative Commons licence, unless indicated otherwise in a credit line to the material. If material is not included in the article's Creative Commons licence and your intended use is not permitted by statutory regulation or exceeds the permitted use, you will need to obtain permission directly from the copyright holder. To view a copy of this licence, visit http://creativecommons.org/licenses/by/4.0/ The Creative Commons Public Domain Dedication waiver (http://creativecommons.org/publicdomain/zero/1.0/) applies to the data made available in this article, unless otherwise stated in a credit line to the data. 


\begin{abstract}
(Continued from previous page)
Conclusions: The prevalence of oral impacts was moderate but higher among the non-Maasai- than Maasaiadolescents attending rural primary schools in the Maasai population areas of Tanzania. This study also confirmed socioeconomic and oral clinical disparities in OIDP, some of which differed according to ethnicity. Caries experience and self-reported TMD pain associated more strongly with OIDP among the non-Maasais than among the Maasais. These results are important for public oral health decision makers who plan strategies for optimal primary oral health care and quality of life among adolescents belonging to minority groups in Tanzania.
\end{abstract}

Keywords: Adolescents, Maasai population areas, Oral diseases, Oral impacts on daily performance, And sociodemographic factors

\section{Background}

In a global perspective, oral health among adolescents has improved during recent decades. However, oral diseases like dental caries and erosion as well as dental fluorosis and periodontal diseases still prevail in certain groups and particularly so in underprivileged societies [1-3]. Studies have confirmed that oral diseases have a negative impact on the quality of life and well-being of adolescents [4-6]. Evidence suggests a gap between professional and subjective evaluations of oral health, possible affecting for example treatment need [7].

Recognizing the growing importance of quality of life measures in health care, oral health related quality of life (OHRQoL) inventories are available to address functional, psychological and social consequences of oral diseases and also to complement clinical measures and evaluate treatment outcomes [8-10]. Adulyanon et al. [11] developed the Oral impact on daily performance (OIDP) inventory, one of the most commonly used OHRQoL instruments, to be used either as a generic or a disease specific measure of oral health related quality of life. The OIDP inventory is based on the conceptual framework of the World Health Organization's International Classification of Impairments, Disabilities and Handicaps, ICIDH [12], and has been amended for use in dentistry by Locker [13]. This inventory covers the ultimate disability and handicap dimensions in the ICIDH model and includes 8 items assessing physical, psychological, and social dimensions of daily living [11]. Two versions of the OIDP inventory have been applied in the literature, one for adults and another one for children and adolescents. The Child OIDP was developed to fit children's cognitive stage of development and was initially tested among 11-12 year old school children in Thailand [14]. This inventory has been widely applied across low and high-income countries [15-17] and has shown acceptable psychometric properties when applied to adolescent populations globally $[6,15,18]$.

However, its application in minority groups, such as the Maasai, is scarce although indigenous populations around the world experience disproportionate burden of oral diseases and conditions [16]. Moreover, the clinical and socio-demographic distribution of OIDP have not been investigated to the same extent in adolescents as in adults [17]. Thus, information of the performance of OHRQoL instruments across socio-cultural minority groups within and across countries has been requested [6].

The Maasai is a unique and popular tribe due to their long preserved culture. Despite education, civilization and western cultural influences, the Maasai people have clung to their traditional way of life [19]. In Tanzania, The Maasais are considered socially disadvantaged because the Maasai reside in a semi-arid ecology prone to erratic rainfall and periodic drought [20]. Such vulnerability may lead to high food insecurity and poor health outcomes [21]. In addition, the Maasai communities tend to live in remote rural areas and also have a relatively poor command of Swahili, the national language of Tanzania. These factors decrease opportunities for obtaining good health services and educational attainment and might thus affect their well-being and quality of life [22].

To the best of our knowledge, no retrievable data/information considers evaluation of OHRQoL in adolescents living in Maasai populated areas of Tanzania. Focusing on Maasai and non-Maasai adolescents and using the Child OIDP inventory, this study aimed to estimate the prevalence of oral impacts and to identify important clinical- and socio-demographic covariates. In addition, this study compares Maasai and non-Maasai adolescents regarding any association of sociodemographic and clinical covariates with oral impacts on daily performances.

\section{Methods}

\section{Study design and participants}

A cross-sectional study was conducted among 12-14year-old adolescents in Maasai populated areas of Monduli and Longido districts, in the Arusha region, Tanzania, from June to November 2016. A list of all primary schools was obtained from both districts (including 100 schools). Urban and private schools were excluded due to the reason that the majority of Maasais live in rural remote areas and are relatively poor and therefore 
won't be able to bring their children in private schools which are relatively expensive. The inclusion criteria were therefore, the adolescents expected to be in age ranging from 12 to 14 year old attending rural public primary schools of Monduli and Longido districts. The exclusion criteria were adolescents attending urban and private primary schools, those who were absent during the interview/oral examination day and those with difficulties in learning. After excluding urban and private schools, 23 (13 from Monduli and 10 from Longido) from a total of 66 (38 from Monduli and 28 from Longido), eligible rural public primary schools were randomly selected using a one-stage cluster sample design with school as the primary sampling unit. A class expected to contain adolescents aged 12-14 years was identified (6th grade) in each selected school. All adolescents available in the identified classes were invited to participate. The sample size was estimated based on the assumption that the prevalence of dental erosion among adolescents was $50 \%$. The estimated minimum sample size for this study, 845 adolescents was obtained by assuming a margin error of $5 \%$ and, confidence intervals of $95 \%$. Details about the sampling technique have been described elsewhere [23]. Thus, in this study, we did a secondary analysis of a study planned for other purposes. Briefly, we invited a total of 989 adolescents to participate in the study and 930 of them accepted this invitation. The final sample included 906 adolescents after having excluded 24 due to too low or high age, giving a response rate of $91.6 \%$.

\section{Interview and questionnaires}

Closed- and open-ended questions were used to assess information in face- to- face interviews. The interview schedule was constructed in English, translated into Swahili and back-translated to English independently by qualified translators from the University of Dar Es Salaam, Tanzania. A pilot test was performed with a group of 50 adolescents aged 12-14 years who were not included in the main study. Two trained medical nurses performed face-to-face interviews in Swahili/Maa (Maasai language) in a school setting. Each adolescent was interviewed separately, inside a classroom or outside the classroom (under a tree), in order to achieve privacy.

Socio-demographic factors were assessed in terms of age, ethnicity, sex, place of residence, mother's education, household socio-economic status (perceived affluence of my household) and household wealth index [24]. Ethnicity was assessed by asking "what is your ethnic group?" During analysis, the response ethnical categories $1=$ Maasai, $2=$ Meru, $3=$ Arusha and $4=$ others were dichotomized to $1=$ Maasai (from option 1 ) and $2=$ nonMaasai (from option 2, 3 and 4). Parents' education was assessed by asking what is the highest level of school your mother/father has attended? Response categories were (0) none, (1) she/he started but did not complete primary school, (2) completed primary school (3) she/he started but did not complete secondary school, (4) she/ he completed secondary school, (5) she/he started but did not complete college/university, (6) completed college/university, (7) I don't know. For analyses, the options were dichotomized as (0) for low education (from options 0, 1, 2, 3 and 7) and (1) for high education (from options 4, 5 and 6). The wealth index was constructed by assessing the presence of durable household assets which indicate family wealth (i.e. radio, television, refrigerator, mobile telephone, cupboard, bicycle and motorcycle). These were recorded as (Yes) "available and in working condition" or (No) "not available and/or not in working condition" and then the principle component analysis (PCA) method was used to construct a wealth index [24]. Using the first component, we categorized the wealth index into 1st quartile, 2nd quartile, 3rd quartile and 4th quartile implying the poorest, poorer, less poor and least poor, respectively. The wealth index is a measure of a household's cumulative living standard, usually calculated by summing up data on a household's ownership of selected assets. PCA works best when the household asset variables are correlated to each other and when the distribution of variables varies across the households. It is those assets that are more unequally distributed between households that are given more weight [25]. For example, assets owned by majority of households would exhibit no variation between households and would be zero weighted and thus of no use in differentiating the wealth of a particular family. Therefore in our study we excluded some of the assets eg animals they had due to the reason that they were owned by majority of communities.

Oral health related quality of life was measured using a Kiswahili (Tanzania national language) version of the eight item Child OIDP inventory, previously shown to be reliable and valid when applied to adolescents in Tanzania [6]. The Child OIDP frequency index referred to difficulty carrying out eight daily life activities "During the past 3 months, how often have problems with your mouth or teeth caused you any difficulty with; eating and enjoying food, speaking and pronouncing clearly, cleaning teeth, sleeping and relaxing, smiling and laughing, emotional status, socialization and contact with people. The original responses were (0) never, (1) once or more a month, (2) once or more a week and (3) every day/nearly every day. In the statistical analyses, the items were dichotomized as 0 not affected (comprising original responses 0 ) and 1 affected (comprising original responses 1,2 and 3). A Child-OIDP simple count (SC) score (range 0-8) was constructed by summing the dichotomized frequency items of (0) not affected and (1) 
affected and subsequently dichotomized into 0 (no impacts) and 1 (at least one impact). In its original form, OIDP scores are calculated by multiplying frequency and severity scores of daily performances [26]. However, evidence suggests the use of either frequency or severity scores for reasons of simplicity and efficiency [26]. The internal consistency reliability (Cronbach's alpha based on standardized items) for the child OIDP inventory was 0.82 , which is in agreement with previous figures $(0.84$ to 0.85 ) from Tanzania [5, 27]. Validity of OIDP is further confirmed in this study by associations with clinical variables in the expected direction.

The two epidemiological questions regarding temporomandibular disorder pain (2Q/TMD), were: "Do you have pain in your temple, face, jaw or jaw joint once a week or more?" and "Does it hurt once a week or more when you open your mouth or chew?" The response was either "yes" or "no" and positive answer to any of the two questions was considered affirmative to self-reported TMD pain diagnosis [28]. Thus, a positive answer to one or both of the two epidemiological questions was recorded as $2 \mathrm{Q} / \mathrm{TMD}>0$ and a negative answer to both epidemiological questions was recorded as $2 \mathrm{Q} / \mathrm{TMD}=0$.

\section{Oral clinical examination}

All clinical examinations were performed by the first author (LS) under natural day light with the adolescent sitting on a chair. The teeth were cleaned and dried by sterile gauze and isolated by cotton rolls. Disposable mouth mirrors and probes were used. The examiner was trained and calibrated at the Department of Clinical Dentistry, University of Bergen, Norway.

Details considering the clinical oral examination have been described elsewhere [23]. Oral hygiene was assessed using the Simplified Oral Hygiene Index (OHIS) [29]. Plaque and calculus was assessed on teeth (16, 11, 26, 36, 31 and 46). The scores were (0) for no plaque/calculus present, (1) for plaque or supra-gingival calculus covering not more than one third of the tooth surface, (2) for plaque or supra-gingival calculus covering more than one third but less than two thirds of the tooth surface, and (3) for plaque or supra-gingival calculus covering more than two thirds of the tooth surface. For each individual, the plaque and calculus scores were summed up and divided by total number of teeth examined to obtain the Simplified Debris Index (DI-S) and simplified calculus index (CI-S). The OHI-S was constructed by summing up the DI-S and CI-S. During analysis the OHI-S scores were dichotomized into $1=\operatorname{good}$ oral hygiene $(\mathrm{OHI}-\mathrm{S}<1)$ and $2=$ poor oral hygiene $(\mathrm{OHI}-\mathrm{S} \geq 1)$. Gingival health was assessed by Gingival Bleeding Index (GBI) and was recorded as positive or negative following a gentle probing on gingival sulcus of the index teeth after $10 \mathrm{~s}$ [30]. Dental caries was assessed according to criteria specified by WHO [31] and was recorded as 0-Sound, 1-Decayed, 2-Filled, with decay, 3Filled, no decay, 4-Missing due to caries, 5-Missing for other reason, 6-Fissure sealant, 7-Bridge abutment, special crown or veneer/implant, 8-Unerupted tooth (crown)/unexposed root, 9-Not recorded. Dental fluorosis was assessed by Thylstrup- Fejerskov - index (TFindex) [32] and was recorded as score 0 to 9 score with score 0 - not affected and score 1-9 showing varying degree of dental fluorosis. Dental erosion on palatal and facial surfaces of maxillary anterior teeth was recorded according to Johansson et al. [33], recording as score 0 to 4 , with score 0 not affected by erosion and score 1-4 affected by dental erosion at different levels. Grading of first molar cuppings by Hasselkvist et al. [34], recorded as score 0 to 4 , with score 0 no cupping and score $1-4$ varying degree of cuppings. Tooth wear was graded as a full mouth recording of occlusal/incisal surfaces according to Carlsson et al. [35], recorded as score 0 to 4 , with score 0 no tooth wear and score $1-4$ varying degree of tooth wear.

The inter-examiner (between LS and AKJ) Cohen's Kappa for dental erosion in all examined teeth surfaces was $82.4 \%$. Duplicate clinical examinations (intra-examiner concordance), 3 weeks apart, including 93 randomly selected participants, gave a Kappa value for caries experience (DMFT $>0$ ), dental fluorosis (TF-index) and dental erosion of 98.3, 86.8 and 69.4, respectively.

\section{Statistical analysis}

The Statistical Package for Social Sciences (SPSS) for PC version 24 (IBM corporation, Armonk, NY, USA) was used to analyze the data. STATA 14.2 (Stata corporation, Lakeway drive college station, Texas, USA) was used to adjust for cluster effect of school. Bivariate analysis was performed by cross tabulations and Pearson's chi-square statistical test. Inter- and intra-examiner concordances were determined using percentage agreement and Cohen's Kappa. Internal consistency reliability was assessed using Cronbach's alpha. Stepwise multiple variable logistic regression analysis (Odds Ratio and 95\% CI) was conducted with OIDP regressed on sociodemographic and oral clinical variables that were statistically significantly associated with OIDP in crude (unadjusted) analysis. In each step Nagelkerke's $R^{2}$ was calculated which denotes a pseudo $R$ square that generalize the coefficient of determination with values between 0 and 1 where 0 denotes that the model do not explain anything of the variation- whereas 1 denotes a model explaining all variation in the dependent variable. The effect of two -way interaction terms between ethnic group and sociodemographic- and clinical variables on OIDP was tested to explore whether any association of socio- 
demographic- and clinical variables with OIDP differed between the ethnic groups.

\section{Results \\ Sample profile}

A total of 906 (56.1\% females), 12-17-year-old (mean age 13.4 years SD 1.2) adolescents attending grade 6 were interviewed and underwent an oral clinical examination at school. Out of these 906, 479 (52.9\%) were from Monduli district, 721 (79.6\%) belonged to the Maasaiand $185(20.4 \%)$ to the non-Maasai ethnic groups. Table 1 depicts the percentage distribution of study participants' sociodemographic- and clinical characteristics in the pooled sample and according to Maasai and nonMaasai ethnicity. A majority (91.2\%) of the adolescents were dental caries free $(\mathrm{DMFT}=0)$ and $48.6 \%$ of the adolescents had severe dental fluorosis (TF score 5-9). A total of $11.8 \%$ of the adolescents self-reported Temporomandibular Disorder pain $(2 \mathrm{Q} / \mathrm{TMD}>0)$. Most sociodemographic and clinical characteristics differed statistically significantly by ethnic group (Table 1).

\section{OIDP by socio-demographic and oral clinical features}

A total of 143/906 (15.8\%) of adolescents investigated reported at-least one oral impact on daily performances (OIDP $>0)$. The frequency of the reported impacts was: eating and enjoying food (7.9\%), speaking and pronouncing clearly $(4.4 \%)$, cleaning teeth (10.5\%), sleeping and relaxing $(3.9 \%)$, smiling and laughing $(2.0 \%)$, maintaining usual emotional state $(2.1 \%)$, carrying major school work or social role $(2.2 \%)$ and enjoying contact with people (2.1\%) (not presented in table).

As depicted in Table 2, socio-demographic and clinical features in terms of district of residence, ethnicity and wealth index and oral hygiene status, DMFT (Decayed Missing Filled Teeth), dental fluorosis and self-reported TMD pain status associated statistically significantly with oral impacts $(\mathrm{OIDP}>0)$. Oral impacts were more frequently reported by adolescents from Monduli districts than among those from Longido (21.9\% versus $8.9 \%, p<0.001)$. Oral impacts were most frequently reported among participants with poor oral hygiene status, caries experience (DMFT $>0)$ and self-reported TMD pain.

Table 3 depicts adjusted odds ratios (OR) and 95\% CI for OIDP (Oral Impacts on Daily Performace) by sociodemographic features and oral diseases/problems. District of residence, sex, ethnicity and wealth index were entered in step 1, providing a model fit of Nagelkerke's $R^{2}=0.103$, Model Chi-Square $=55.407, \mathrm{df}=4$ and $p<0.001$. District, ethnicity, wealth index and age were statistically significantly associated with OIDP in the first step of the model. Entering oral hygiene status, DMFT> 0 , dental fluorosis (TF 5-9) and 2Q/TMD $>0$ in the second step improved model fit to Nagelkerke's $R^{2}=0.199$, model Chi-square $=110.178, \mathrm{df}=8$ and $p<0.001$. In the second step of the model, district $(\mathrm{OR}=0.4$, CI $0.3-0.7)$, ethnicity $(\mathrm{OR}=1.6, \mathrm{CI} 1.1-2.3)$, wealth index $(\mathrm{OR}=2.0$, CI 1.2-3.3), oral hygiene status $(\mathrm{OR}=0.7$, CI $0.5-0.9)$, DMFT $>0 \quad(\mathrm{OR}=3.1, \quad \mathrm{CI} 2.1-4.5)$ and $2 \mathrm{Q} / \mathrm{TMD}>0$ $(\mathrm{OR}=3.9$, CI 2.4-6.2) were significant covariates of OIDP $>0$. Adjusting for cluster effect did not change the ORs, but there was a small widening of the confidence intervals, only.

Statistically significant effects of two-way interactions, occurred for ethnicity $\mathrm{x}$ age $(\mathrm{OR}=4.4,95 \% \mathrm{CI} 1.7-11.3)$, ethnicity $\mathrm{x}$ dental caries $(\mathrm{OR}=4.6,95 \% \mathrm{CI} 2.1-10.0)$ and ethnicity $x$ self-reported TMD pain $(\mathrm{OR}=8.0,95 \% \mathrm{CI}$ 3.6-17.8) (Table 4). As shown in Table 5, stratified logistic regression analysis by ethnic group revealed that among non-Maasais only, older adolescents were more likely than their younger aged counterparts to report at least one OIDP (OR $=3.7,95 \%$ CI 1.1-12.8). Adolescents with (dental caries) DMFT>0 were 2.8 (95\% CI 1.4-5.5) and 3.3 (95\% CI 1.2-9.0) times more likely to report oral impacts in the Maasai and non-Maasai groups, respectively. Maasai and non-Maasai adolescents with self-reported TMD pain were more likely to report oral impacts than their counterparts with no self-reported TMD pain. The corresponding OR and 95\% CI were 3.0 $(1.7-5.2)$ and $9.0(3.3-25.0)$, respectively.

\section{Discussion}

This study is among the first to estimate the prevalenceand socio-demographic- and clinical covariates of oral impacts on daily performances among adolescents living in Maasai population areas of the Arusha region in Tanzania. The prevalence of OIDP was moderate and amounted to about 15 and 20\% among the Maasai and non-Maasai ethnic groups, respectively. Independent of ethnic group belongingness, adolescents who were the least poor according to the wealth index utilized and those who presented with oral diseases were most likely to report oral impacts. The present findings revealed significant differences by ethnic groups in the relationships between socio-demographic- and clinical covariates and oral impacts. Older adolescents were more likely than their younger counterparts to report oral impacts among the non-Maasais only. Dental caries experience and selfreported TMD pain was significantly associated with oral impacts among both ethnic groups but more strongly among the non-Maasais than among their Maasai counterparts.

In this study, about $16 \%$ reported at least one oral impact on daily performance during the past 3 months (15\% among Maasais and 20\% among non-Maasais). These prevalence rates are lower than those reported previously among adolescents of similar ages in sub Saharan Africa ranging from 29 to $62 \%$ [4-6, 36]. Higher 
Table 1 Frequency distribution of sociodemographic and clinical characteristics in a total sample $(n=906)$ and by ethnicity

\begin{tabular}{|c|c|c|c|c|}
\hline Variable & Total \% (n) & Maasai \% (n) & Non-Maasai \% (n) & ${ }^{*} \boldsymbol{P}$-value \\
\hline \multicolumn{5}{|l|}{ District of residence } \\
\hline Monduli & $52.9(479)$ & $58.0(418)$ & $33.0(61)$ & \\
\hline Longido & $47.1(427)$ & $42.0(303)$ & $67.0(124)$ & $<0.001$ \\
\hline \multicolumn{5}{|l|}{ Sex } \\
\hline Male & 43.9 (398) & $43.1(311)$ & $47.0(87)$ & \\
\hline Female & $56.1(508)$ & $56.9(410)$ & $53.0(98)$ & 0.341 \\
\hline \multicolumn{5}{|l|}{ Age } \\
\hline $12-14$ years & $87.3(777)$ & $86.5(610)$ & $90.3(167)$ & \\
\hline $15-17$ years & $12.7(113)$ & $13.5(95)$ & 9.7 (18) & 0.173 \\
\hline \multicolumn{5}{|l|}{ Wealth index } \\
\hline Poorest & $48.8(438)$ & $57.3(408)$ & $16.2(30)$ & \\
\hline Least poor & $51.2(459)$ & $42.7(304)$ & $83.8(155)$ & $<0.001$ \\
\hline \multicolumn{5}{|l|}{ Mother's education } \\
\hline Low ( $\leq$ primary school) & $861(95.0)$ & $96.8(698)$ & $88.1(163)$ & \\
\hline High ( $\geq$ secondary school) & $45(5.0)$ & $3.2(23)$ & $11.9(22)$ & $<0.001$ \\
\hline \multicolumn{5}{|l|}{ Oral hygiene status } \\
\hline Poor & $65.6(594)$ & $68.5(508)$ & $54.1(100)$ & \\
\hline Good & $34.4(312)$ & $31.5(213)$ & $45.9(85)$ & $<0.001$ \\
\hline \multicolumn{5}{|l|}{ Gingival bleeding } \\
\hline No & $59.1(535)$ & $55.6(401)$ & $72.4(134)$ & \\
\hline Yes & $40.9(371)$ & $44.4(320)$ & $27.6(51)$ & $<0.001$ \\
\hline \multicolumn{5}{|l|}{ DMFT } \\
\hline $\mathrm{DMFT}=0$ & $91.2(826)$ & $92.6(668)$ & $85.4(158)$ & \\
\hline DMFT $>0$ & $8.8(80)$ & $7.4(53)$ & $14.6(27)$ & 0.002 \\
\hline \multicolumn{5}{|l|}{ Dental fluorosis } \\
\hline TF score $0-4$ & $51.4(466)$ & 47.9 (345) & $65.4(121)$ & \\
\hline TF score 5-9 & $48.6(440)$ & 52.1 (376) & $34.6(64)$ & $<0.001$ \\
\hline \multicolumn{5}{|l|}{ Dental erosion } \\
\hline Grade 0 & $69.8(632)$ & $73.2(528)$ & $56.2(104)$ & \\
\hline Grade $>0$ & 30.2 (274) & 26.8 (193) & $43.8(81)$ & $<0.001$ \\
\hline \multicolumn{5}{|l|}{ Tooth wear } \\
\hline Grade 0 & $54.0(489)$ & 55.1 (397) & $49.7(92)$ & \\
\hline Grade $>0$ & $46.0(417)$ & 44.9 (324) & $50.3(93)$ & 0.194 \\
\hline \multicolumn{5}{|l|}{ TMD pain } \\
\hline $2 \mathrm{Q} / \mathrm{TMD}=0$ & 88.2 (799) & $88.8(640)$ & $85.9(159)$ & \\
\hline $2 \mathrm{Q} / \mathrm{TMD}>0$ & 11.8 (107) & $11.2(81)$ & $14.1(26)$ & 0.289 \\
\hline
\end{tabular}

*Pearson's Chi-square test

prevalence of OIDP has also been reported among the adolescents from other countries, for example Brazil (37\%), Italy (67\%), China (46\%) and Thailand (85\%) [37-40]. The relatively low prevalence of oral impacts among Maasai- and non-Maasai adolescesnts is most likely related to the low occurrence of oral diseases generally and dental caries particularly observed in those populations. In accordance with some previous reports from sub Saharan Africa, difficulties with eating food and cleaning teeth were the most frequent oral impacts affecting adolescents in this study [4-6].

The present differences in OIDP across sociodemographic- and clinical variables confirm the social and clinical gradients observed in oral health of adolescent/ adult populations worldwide [41, 42]. Although Longido district was most populated with non-Maasai 
Table 2 Distribution of OIDP according to sociodemographic features and clinical indicators of oral diseases/problems

\begin{tabular}{|c|c|c|c|}
\hline Variable & Categories & OIDP $>0 \%(n)$ & $P$-value* \\
\hline \multirow[t]{2}{*}{ District of residence } & Monduli & $21.9(105)$ & \\
\hline & Longido & $8.9(38)$ & $<0.001$ \\
\hline \multirow[t]{2}{*}{ Sex } & Female & $14.2(72)$ & \\
\hline & Male & $17.8(71)$ & 0.133 \\
\hline \multirow[t]{2}{*}{ Age } & $12-14$ years & $15.2(118)$ & \\
\hline & $15-17$ years & $22.1(25)$ & 0.061 \\
\hline \multirow[t]{2}{*}{ Ethnicity } & Maasai & $14.6(105)$ & \\
\hline & Non-Maasai & $20.5(38)$ & 0.047 \\
\hline \multirow[t]{2}{*}{ Wealth index } & Poorest & $11.9(52)$ & \\
\hline & Least poor & $19.4(89)$ & 0.002 \\
\hline \multirow[t]{2}{*}{ Mother's education } & Low ( $\leq$ primary school) & $15.4(133)$ & \\
\hline & High ( $\geq$ secondary school) & $22.2(10)$ & 0.224 \\
\hline \multirow[t]{2}{*}{ Oral hygiene status } & Poor & $18.2(108)$ & \\
\hline & Good & $11.2(35)$ & 0.006 \\
\hline \multirow[t]{2}{*}{ Gingival bleeding } & No & $14.8(79)$ & \\
\hline & Yes & $17.3(64)$ & 0.313 \\
\hline \multirow[t]{2}{*}{ DMFT } & $\mathrm{DMFT}=0$ & 13.7 (113) & \\
\hline & $\mathrm{DMFT}>0$ & $37.3(30)$ & $<0.001$ \\
\hline \multirow[t]{2}{*}{ Dental fluorosis } & TF score $0-4$ & $11.4(53)$ & \\
\hline & TF score 5-9 & $20.5(90)$ & $<0.001$ \\
\hline \multirow[t]{2}{*}{ Dental erosion } & Grade 0 & $16.8(106)$ & \\
\hline & Grade $>0$ & $13.5(37)$ & 0.215 \\
\hline \multirow[t]{2}{*}{ Tooth wear } & Grade 0 & $14.9(73)$ & \\
\hline & Grade $>0$ & $16.8(70)$ & 0.445 \\
\hline \multirow[t]{2}{*}{ TMD pain } & $2 \mathrm{Q} / \mathrm{TMD}=0$ & $12.3(98)$ & \\
\hline & $2 \mathrm{Q} / \mathrm{TMD}>0$ & $42.1(45)$ & $<0.001$ \\
\hline
\end{tabular}

*Pearson's Chi-square test

adolescents, Longido residents were less likely to report oral impacts than their counterparts in Monduli district. This difference might be attributed to variation in prevalence and severity of oral diseases as well as differences in the socio-demographic distribution between the two districts. Non-Maasais had higher odds of reporting any OIDP than the Maasais and ethnic group was strongly and independently associated with oral impacts after adjustment for oral diseases and socio-demographic factors. Although comparable studies from sub Saharan Africa are lacking, reports from high income countries have shown that non-White individuals or minority ethnic groups are more likely to have oral impacts than their white majority ethnic group counterparts [43, 44]. The influence of ethnicity on oral health is linked to, socioeconomic, behavioral and psychosocial factors that varied across the ethnic groups [45]. In this study, most adolescents were from poor families and lived in rural remote areas where social services are limited. All these exposed them to various risk factors of oral diseases and affected their psychological, social and quality aspects of their life" Moreover, the present findings and also previous ones have shown that non-Maasai adolescents are more frequently affected by oral diseases than their Maasai counterparts [23]. Those from the least poor families were more likely to report oral impacts than those from the poorest families. This is contrary to other studies reporting that the poorest families report most oral impacts $[4,46]$. In this study, adolescents from the least poor families might have the easiest access to sugary foods and thus being those most exposed to development of dental caries. In accordance with the present findings, a previous study reported that Tanzanian adolescents from least poor families, according to the family wealth index, reported dental pain and other oral problems more frequently than their counterparts from the poorest families [5].

In accordance with previous studies but contrary to others, the present one demonstrated a strong and independent association between indicators of oral health 
Table 3 Logistic regression for the association between adolescents' social and clinical characteristics and OIDP, odds ratios (OR) ad 95\% confidence interval (Cl)

\begin{tabular}{|c|c|c|}
\hline Variable & Step 1 OR (95\% Cl) & Step 2 OR $(95 \%$ Cl) \\
\hline \multicolumn{3}{|c|}{ District of residence } \\
\hline Monduli & 1 & 1 \\
\hline Longido & $0.3(0.2-0.4)^{b}$ & $0.4(0.3-0.7)^{b}$ \\
\hline \multicolumn{3}{|l|}{ Age } \\
\hline $12-14$ years & 1 & 1 \\
\hline $15-17$ years & $1.4(1.0-2.1)$ & $1.2(0.9-1.8)$ \\
\hline \multicolumn{3}{|l|}{ Ethnicity } \\
\hline Maasai & 1 & 1 \\
\hline Non-Maasai & $1.7(1.1-2.7)^{\mathrm{b}}$ & $1.6(1.1-2.3)^{b}$ \\
\hline \multicolumn{3}{|l|}{ Wealth index } \\
\hline Poorest & 1 & 1 \\
\hline Least poor & $2.0(1.4-3.0)^{b}$ & $2.0(1.2-3.3)^{b}$ \\
\hline \multicolumn{3}{|c|}{ Oral hygiene status } \\
\hline Poor & & 1 \\
\hline Good & & $0.7(0.5-0.9)^{b}$ \\
\hline \multicolumn{3}{|l|}{ DMFT } \\
\hline $\mathrm{DMFT}=0$ & & 1 \\
\hline DMFT $>0$ & & $3.1(2.1-4.5)^{b}$ \\
\hline \multicolumn{3}{|l|}{ Dental fluorosis } \\
\hline TF $0-4$ & & 1 \\
\hline TF 5-9 & & $1.5(0.9-2.4)$ \\
\hline \multicolumn{3}{|l|}{ TMD pain } \\
\hline $2 \mathrm{Q} / \mathrm{TMD}^{\mathrm{a}}=0$ & & 1 \\
\hline $2 \mathrm{Q} / \mathrm{TMD}>0$ & & $3.9(2.4-6.2)^{b}$ \\
\hline
\end{tabular}

Step 1: model fit Nagelkerke's $R^{2}=0.103$, Model Chi-Square $=55.407$, $\mathrm{df}=4, p<0.001$

Step 2: model fit Nagelkerke's $R^{2}=0.199$, model Chi-square $=110.178$, $\mathrm{df}=8, p<0.001$

${ }^{\mathrm{a}} 2 \mathrm{Q} / \mathrm{TMD}$ Two epidemiological questions regarding TMD pain

${ }^{\mathrm{b}}$ Statistically significant

status, namely dental caries and self-reported TMD pain, and oral impacts [6, 27, 47-49] (Table 3). Moreover, adolescents with good oral hygiene had lower odds than those with poor oral hygiene to report oral impacts. This finding is contrary to other studies from Tanzania which found no significant differences in oral impacts according to level of oral hygiene status $[4,6]$. Poor oral hygiene is an outcome of irregular tooth cleaning and may lead to gingivitis and increase the risk for periodontitis [50], which has a negative impact on oral health related quality of life [51, 52]. Dental caries, if left untreated, can affect adolescent's quality of life through dental pain leading to deterioration in oral functioning, emotional state as well as social roles [53]. The positive association observed between self-reported TMD pain and oral impacts supports findings from previous studies [54-56].
Table 4 Statistically significant effects of two-way interactions between adolescents' social and clinical characteristics and OIDP (cluster adjusted), odds ratios (OR) ad 95\% confidence interval (Cl)

\begin{tabular}{|c|c|}
\hline Variable & Step 2 OR $(95 \%$ Cl) \\
\hline \multicolumn{2}{|l|}{ Ethnicity $x$ age } \\
\hline Maasai $\times 12-14$ years & 1 \\
\hline Non Maasai $\times 15-17$ years & $4.4(1.7-11.3)^{b}$ \\
\hline \multicolumn{2}{|l|}{ Ethnicity x DMFT } \\
\hline Maasai $\times \mathrm{DMFT}=0$ & 1 \\
\hline Non Maasai x DMFT>0 & $4.6(2.1-10.0)^{b}$ \\
\hline \multicolumn{2}{|l|}{ Ethnicity $x$ TMD pain } \\
\hline Maasai $\times 2 \mathrm{Q} / \mathrm{TMD}^{\mathrm{a}}=0$ & 1 \\
\hline Non-Maasai $\times 2 \mathrm{Q} / \mathrm{TMD}>0$ & $8.0(3.6-17.8)^{b}$ \\
\hline
\end{tabular}

The similarity in these findings indicates that selfreported TMD pain affects OHRQoL across various populations. The OIDP index measures only ultimate impacts and statistically significant relationships can be difficult to demonstrate when the prevalence of one of the covariates is low. Thus, it is noteworthy that the observed associations between clinical indicators and oral impacts were statistically significant despite a relatively low prevalence of oral impacts in the present study population. The prevalence of tooth wear/dental erosion in this population was relatively low and did not associate with oral impacts on daily performance. Similar negative findings between oral health related quality of life indicators and low prevalence of tooth wear have been reported elsewhere [57]. On the other hand, if prevalence and severity of tooth wear increases in the future caused by changes in behavioral pattern and/or socioeconomic conditions, it could result in an impact on oral health related quality of life as reported by others [58]. In the studied society, it is likely that today's traditional lifestyle and relatively low prevalence oral diseases will be subjected to a change into a more modern way of living in the future. In this regard, harmful choices of behavior may arise which may increase the risk for development oral diseases. This perspective has to be considered in future public dental health planning.

\section{Study limitations}

The present study used a large sample size providing more reliable results with greater precision and power. In addition, the study provided a detailed oral clinical examination and used an oral quality of life inventory previously validated for use in Tanzanian and other nonoccidental context. Although schools were selected randomly and in spite of a high response rate, the possibility of selection bias cannot be overlooked. The rigorous 
Table 5 Logistic regression for the association between adolescents' social and clinical characteristics and OIDP, according to ethnic belongingness (cluster adjusted). Odds ratios (OR) ad 95\% confidence interval (Cl)

\begin{tabular}{|c|c|c|c|c|}
\hline \multirow[t]{2}{*}{ Variable } & \multicolumn{2}{|l|}{ Maasai } & \multicolumn{2}{|l|}{ Non-Maasai } \\
\hline & Step 1 OR $(95 \%$ Cl) & Step 2 OR $(95 \% \mathrm{Cl})$ & Step 1 OR $(95 \%$ Cl) & Step 2 OR $(95 \%$ Cl) \\
\hline \multicolumn{5}{|c|}{ District of residence } \\
\hline Monduli & 1 & 1 & 1 & 1 \\
\hline Longido & $0.2(0.1-0.4)^{b}$ & $0.4(0.2-0.7)^{b}$ & $0.7(0.3-1.7)$ & $0.8(0.3-2.5)$ \\
\hline \multicolumn{5}{|l|}{ Age } \\
\hline $12-14$ years & 1 & 1 & 1 & 1 \\
\hline $15-17$ years & $1.1(0.6-2.0)$ & $0.9(0.5-1.7)$ & $3.1(1.0-9.1)$ & $3.7(1.1-12.8)^{b}$ \\
\hline \multicolumn{5}{|l|}{ Wealth index } \\
\hline Poorest & 1 & 1 & 1 & 1 \\
\hline Least poor & $2.0(1.3-3.0)^{b}$ & $1.9(1.2-2.9)^{b}$ & $1.4(0.4-4.5)$ & $1.7(0.5-6.3)$ \\
\hline \multicolumn{5}{|c|}{ Oral hygiene status } \\
\hline Poor & & 1 & & 1 \\
\hline Good & & $0.6(0.3-1.0)$ & & $0.6(0.3-1.5)$ \\
\hline \multicolumn{5}{|l|}{ DMFT } \\
\hline $\mathrm{DMFT}=0$ & & 1 & & 1 \\
\hline $\mathrm{DMFT}>0$ & & $2.8(1.4-5.5)^{b}$ & & $3.3(1.2-9.0)^{b}$ \\
\hline \multicolumn{5}{|l|}{ Dental fluorosis } \\
\hline TF $0-4$ & & 1 & & 1 \\
\hline TF 5-9 & & $1.7(1.0-2.9)$ & & $1.0(0.4-2.7)$ \\
\hline \multicolumn{5}{|l|}{ TMD pain } \\
\hline $2 \mathrm{Q} / \mathrm{TMD}^{\mathrm{a}}=0$ & & 1 & & 1 \\
\hline $2 \mathrm{Q} / \mathrm{TMD}>0$ & & $3.0(1.7-5.2)^{b}$ & & $9.0(3.3-25.0)^{\mathrm{b}}$ \\
\hline
\end{tabular}

${ }^{\mathrm{a}} \mathrm{Q}$ /TMD Two epidemiological questions regarding TMD pain

${ }^{\mathrm{b}}$ Statistically significant

selection criteria utilized might have resulted in a recruited study population that was not strictly representative of the general adolescent population in the study area. The structured interviewer-administered schedule used to assess self-reported data might be subject to social desirability, acquiescence, and recall biases. Attempts were made to minimize these biases by informing the participants that their responses were confidential and that no-one could link their names to their responses. Furthermore, the cross-sectional design utilized makes it difficult to establish causal relationships. In addition, our plan was to invite all adolescents aged 1214 years. However, during interview we invited all available adolescents without separating them according to age. During analysis we realized that the age range was between 11 to 26 years. So to reduce this wide age range we decided to exclude those below 12 years and above 17 years.

\section{Conclusion}

The prevalence of oral impacts was moderate but higher among the non-Maasai-than Maasai- adolescents, attending rural primary schools in the Maasai population areas of Tanzania. This study also confirmed socioeconomic and oral clinical disparities in OIDP, some of which differed according to ethnicity. Caries experience and self-reported TMD pain associated more strongly with OIDP among the non-Maasais than among the Maasais. The results are important for public oral health decision makers who plan strategies for optimal oral health and quality of life among adolescents belonging to minority groups in Tanzania. This is important for the prevention of oral diseases and improvement of oral health related quality of life among the adolescents of the under privileged ethnic groups.

\section{Abbreviations}

2Q/TMD: Two epidemiological Questions regarding Temporomandibular Disorder pain; $2 \mathrm{Q} / \mathrm{TMD}>0$ : A positive response to any or both of the two epidemiological questions regarding Temporomandibular Disorder pain; 2Q/ $T M D=0$ : A negative response to both epidemiological questions regarding Temporomandibular Disorder pain; Cl: Confidence interval; C-OIDP: Child-oral impact on daily performance; CI-S: Simplified calculus index; D: Design effect; DI-S: Simplified Debris Index; DMFT: Decayed Missing Filled Tooth; GBI: Gingival Bleeding Index; OHI-S: Simplified Oral Hygiene Index; OHRQOL: Oral health related quality of life; OIDP: Oral impact on daily performance; OIDPSC: Oral Impact on Daily Performance Simple Count score; 
OR: Odds Ratio; PCA: Principal Component Analysis; SD: Standard deviation; SPSS: Statistical Package for Social Sciences; TF-index: Thylstrup-Fejerskovindex; TMD: Temporomandibular disorder; WHO: World Health Organisation

\section{Acknowledgements}

We would like to thank the district education officers of both Monduli and Longido district councils for field work support. Thanks to Rose Lukumay and Ciriel Palanjo who were responsible for the data collection in Monduli district and to Joyce Mwanga and Wema Laizer who collected data in Longido district. We also give our sincere thanks to parents, teachers and study participants for making this study happen.

\section{Authors' contributions}

LS: principal investigator, designed the study, collected the data, performed the statistical analyses, and wrote the manuscript. AKJ: main supervisor, designed the study, guided the statistical analyses and writing the manuscript. AJ: participated in the design of the study, guided the statistical analyses and writing the manuscript. IK: Co-supervisor, participated in the design of the study and provided valuable guidance in the data collection and writing the manuscript. ANA: Co-supervisor, designed the study, guided the statistical analyses and writing the manuscript. The author(s) read and approved the final manuscript.

\section{Funding}

The research was fully funded by Department of Clinical Dentistry, University of Bergen, Norway.

\section{Availability of data and materials}

The datasets used and/or analysed during the current study are available from the corresponding author on request.

\section{Ethics approval and consent to participate}

Ethical clearance was obtained prior to study from the ethical research committee in Norway (REK VEST, reference number 2015/2477) and the Medical Research Coordinating Committee of Ministry of Health and Social Welfare in Tanzania (reference number NIMR/HQ/R.8a/NOL.IX/2214). Permission to work with adolescents was obtained from Ministry of Education and Vocational Training through Monduli and Longido district councils and their respective educational authorities. Participation was voluntary and without compensation. Prior to the participation, informed written signed consent was obtained from their parents. Only adolescents who assented and with signed consent from their parents were invited to participate in the study. If needed relevant advice and/or referral to the district hospital were given free of charge.

\section{Consent for publication}

Not applicable.

\section{Competing interests}

The authors declare that they have no competing interests.

\section{Author details}

'Department of Clinical Dentistry - Cariology, Faculty of Medicine, University of Bergen, Bergen, Norway. ${ }^{2}$ Department of Clinical Dentistry Prosthodontics, Faculty of Medicine, University of Bergen, Bergen, Norway. ${ }^{3}$ Department of Restorative Dentistry, School of Dentistry, Muhimbili University of Health and Allied Sciences, Dar Es Salaam, Tanzania. ${ }^{4}$ Department of Clinical Dentistry - Community Dentistry, Faculty of Medicine, University of Bergen, Bergen, Norway.

Received: 30 August 2019 Accepted: 9 June 2020 Published online: 12 June 2020

\section{References}

1. Petersen PE. The world Oral health report 2003: continuous improvement of oral health in the 21st century - the approach of the WHO Global Oral Health Programme. Community Dent Oral Epidemiol. 2003;31:3-24.

2. Abid A, Maatouk F, Berrezouga L, Azodo C, Uti O, El-Shamy H, Oginni A. Prevalence and severity of oral diseases in the Africa and Middle East region. Adv Dent Res. 2015;27:10-7.
3. Petersen PE, Bourgeois D, Ogawa H, Estupinan-Day S, Ndiaye C. The global burden of oral diseases and risks to oral health. Bull World Health Organ. 2005;83:661-9.

4. Mbawalla HS, Masalu JR, Åstrøm AN. Socio-demographic and behavioural correlates of oral hygiene status and oral health related quality of life, the Limpopo - Arusha school health project (LASH): a cross-sectional study. BMC Pediatr. 2010;10:87

5. Mashoto KO, Astrom AN, David J, Masalu JR. Dental pain, oral impacts and perceived need for dental treatment in Tanzanian school students: a crosssectional study. Health Qual Life Outcomes. 2009;7:73.

6. Mtaya M, Astrom AN, Tsakos G. Applicability of an abbreviated version of the Child-OIDP inventory among primary schoolchildren in Tanzania. Health Qual Life Outcomes. 2007;5:40.

7. Locker D, Miller Y. Evaluation of subjective oral health indicators. J Public Health Dent. 1994:54:167-76.

8. Locker D. Concepts of oral health, disease and the quality of life. In: Measuring oral health and quality of life. Chapel Hill: University of North Carolina; 1997.

9. Jokovic A, Locker D, Guyatt G. Short forms of the Child Perceptions Questionnaire for 11-14-year-old children (CPQ11-14): development and initial evaluation. Health Qual Life Outcomes. 2006;4:4.

10. Pahel BT, Rozier RG, Slade GD. Parental perceptions of children's oral health: the Early Childhood Oral Health Impact Scale (ECOHIS). Health Qual Life Outcomes. 2007;5:6.

11. Adulyanon S, Vourapukjaru J, Sheiham A. Oral impacts affecting daily performance in a low dental disease Thai population. Community Dent Oral Epidemiol. 1996;24:385-9.

12. Badley EM. The ICIDH: format, application in different settings, and distinction between disability and handicap. A critique of papers on the application of the international classification of impairments, disabilities, and handicaps. Int Disabil Stud. 1987;9:122-5.

13. Locker D. Measuring oral health: a conceptual framework. Community Dent Health. 1988;5:3-18.

14. Gherunpong S, Tsakos G, Sheiham A. Developing and evaluating an oral health-related quality of life index for children; the CHILD-OIDP. Community Dent Health. 2004;21:161-9.

15. Tubert-Jeanin S, Pegon-Machat E, Gremeau-Richard C, M-M L, Tsakos G. Validation of the French version of the Child-OIDP index. Eur J Oral Sci. 2005;113:355-62.

16. Tiwari T, Jamieson L, Broughton J, Lawrence HP, Batliner TS, Arantes R, Albino J. Reducing indigenous oral health inequalities: a review from 5 nations. J Dent Res. 2018;97:869-77.

17. Currie C, Molcho M, Boyce W, Holstein B, Torsheim T, Richter M. Researching health inequalities in adolescents: the development of the Health Behaviour in School-Aged Children (HBSC) family affluence scale. Soc Sci Med. 2008;66: 1429-36.

18. Yusuf H, Gherunpong S, Sheiham A, Tsakos G. Validation of an English version of the Child-OIDP index, an oral health-related quality of life measure for children. Health Qual Life Outcomes. 2006;4:38.

19. Kenya Information Guide. The Maasai tribe. http://www.kenya-informationguide.com/maasai-tribe.html. Accessed 8 Oct 2019.

20. Goldman MJ, Riosmena F. Adaptive capacity in Tanzanian Maasailand: changing strategies to cope with drought in fragmented landscapes. Glob Environ Change. 2013;23:588-97.

21. Lawson DW, Borgerhoff Mulder M, Ghiselli ME, Ngadaya E, Ngowi B, Mfinanga SG, Hartwig K, James S. Ethnicity and child health in northern Tanzania: Maasai pastoralists are disadvantaged compared to neighbouring ethnic groups. PLoS One. 2014;9:e110447.

22. Sika NK, Hodgson DL. In the shadow of the MDGs: pastoralist women and children in Tanzania. Indigenous Aff. 2006;1:30-7.

23. Simangwa LD, Astrom AN, Johansson A, Minja IK, Johansson AK. Oral diseases and socio-demographic factors in adolescents living in Maasai population areas of Tanzania: a cross-sectional study. BMC Oral Health. 2018;18:200.

24. Schellenberg JA, Victora CG, Mushi A, de Savigny D, Schellenberg D, Mshinda $\mathrm{H}$, Bryce J. Inequities among the very poor: health care for children in rural southern Tanzania. Lancet. 2003;361:561-6.

25. McKenzie DJ. Measuring inequality with asset indicators. J Popul Econ. 2005;18:229.

26. Kida IA, Astrom AN, Strand GV, Masalu JR, Tsakos G. Psychometric properties and the prevalence, intensity and causes of oral impacts on daily 
performance (OIDP) in a population of older Tanzanians. Health Qual Life Outcomes. 2006;4:56

27. Mbawalla HS, Mtaya M, Masaku JR, Brudvik P, Astrom A. Discriminative ability of the generic and condition-specific Child-Oral Impacts on Daily Performances (Child-OIDP) by the Limpopo-Arusha School Health (LASH) project: a cross-sectional study. BMC Pediatr. 2011;11:45.

28. Nilsson IM, List T, Drangsholt M. The reliability and validity of self-reported temporomandibular disorder pain in adolescents. J Orofac Pain. 2006:20:138-44.

29. Greene JC, Vermillion JR. The simplified oral hygiene index. J Am Dent Assoc. 1964;68:7-13.

30. Ainamo J, Bay I. Problems and proposals for recording gingivitis and plaque. Int Dent J. 1975:25:229-35.

31. World Health Organization (WHO). Oral health surveys: basic methods. 5th ed. Geneva: WHO; 2013. http://www.who.int/oral_health/publications/ 9789241548649/en/. Accessed 26 Aug 2017.

32. Thylstrup A, Fejerskov O. Clinical appearance of dental fluorosis in permanent teeth in relation to histologic changes. Community Dent Oral Epidemiol. 1978;6:315-28

33. Johansson AK, Johansson A, Birkhed D, Omar R, Baghdadi S, Carlsson GE. Dental erosion, soft-drink intake, and oral health in young Saudi men, and the development of a system for assessing erosive anterior tooth wear. Acta Odontol Scand. 1996;54:369-78.

34. Hasselkvist A, Johansson A, Johansson AK. Dental erosion and soft drink consumption in Swedish children and adolescents and the development of a simplified erosion partial recording system. Swed Dent J. 2010;34:187-95.

35. Carlsson GE, Johansson A, Lundqvist S. Occlusal wear: a follow-up study of 18 subjects with extensively worn dentitions. Acta Odontol Scand. 1985:43:83-90

36. Astrom AN, Okullo I. Validity and reliability of the Oral Impacts on Daily Performance (OIDP) frequency scale: a cross-sectional study of adolescents in Uganda. BMC Oral Health. 2003;3:5.

37. da Cunha IP, Pereira AC, Frias AC, Vieira V, de Castro Meneghim M, Batista MJ, Cortellazzi KL, Bulgareli JV. Social vulnerability and factors associated with oral impact on daily performance among adolescents. Health Qual Life Outcomes. 2017:15:173.

38. Bianco A, Fortunato L, Nobile CG, Pavia M. Prevalence and determinants of oral impacts on daily performance: results from a survey among school children in Italy. Eur J Pub Health. 2010;20:595-600.

39. Hongxing L, List T, Nilsson I-M, Johansson A, Astrøm AN. Validity and reliability of OIDP and OHIP-14: a survey of Chinese high school students. BMC Oral Health. 2014;14:158.

40. Krisdapong S, Sheiham A, Tsakos G. Oral health-related quality of life of 12 and 15-year-old Thai children: findings from a national survey. Community Dent Oral Epidemiol. 2009:37:509-17.

41. Petersen PE. Sociobehavioural risk factors in dental caries - international perspectives. Community Dent Oral Epidemiol. 2005;33:274-9.

42. Sabbah W, Tsakos G, Chandola T, Sheiham A, Watt RG. Social gradients in oral and general health. J Dent Res. 2007:86:992-6.

43. Emmanuelli B, Kucner AA, Ostapiuck M, Tomazoni F, Agostini BA, Ardenghi TM. Racial differences in oral health-related quality of life: a multilevel analysis in Brazilian children. Braz Dent J. 2015;26:689-94.

44. Goncalves H, Gonzalez DA, Araujo CL, Anselmi L, Menezes AM. The impact of sociodemographic conditions on quality of life among adolescents in a Brazilian birth cohort: a longitudinal study. Rev Panam Salud Publica. 2010:28:71-9.

45. Thumboo J, Fong KY, Machin D, Chan SP, Soh CH, Leong KH, et al. Quality of life in an urban Asian population: the impact of ethnicity and socioeconomic status. Soc Sci Med. 2003;56:1761-72.

46. Piovesan C, Antunes JL, Guedes RS, Ardenghi TM. Impact of socioeconomic and clinical factors on child oral health-related quality of life (COHRQoL) Qual Life Res. 2010;19:1359-66.

47. Bernabé E, Tsakos G, Sheiham A. Intensity and extent of oral impacts on daily performances by type of self-perceived oral problems. Eur J Oral Sci. 2007;115:111-6.

48. Kolawole KA, Otuyemi OD, Oluwadaisi AM. Assessment of oral healthrelated quality of life in Nigerian children using the Child Perception Questionnaire (CPQ 11-14). Eur J Paediatr Dent. 2011;12:55.

49. Brown A, Al-Khayal Z. Validity and reliability of the Arabic translation of the child oral-health-related quality of life questionnaire (CPQ (11-14)) in Saudi Arabia. Int J Paediatr Dent. 2006;16:405-11.
50. Chrysanthakopoulos N. Prevalence of gingivitis and associated factors in 1316-year-old adolescents in Greece. Eur J Gen Dent. 2016;5:58-64.

51. Lawrence HP, Thomson WM, Broadbent JM, Poulton R. Oral health-related quality of life in a birth cohort of 32year olds. Community Dent Oral Epidemiol. 2008;36:305-16.

52. Ferreira MC, Dias-Pereira AC, Branco-de-Almeida LS, Martins CC, Paiva SM. Impact of periodontal disease on quality of life: a systematic review. J Periodontal Res. 2017;52:651-65.

53. Krisdapong S, Prasertsom P, Rattanarangsima K, Sheiham A. Relationships between oral diseases and impacts on Thai schoolchildren's quality of life: evidence from a Thai national oral health survey of 12- and 15-year-olds. Community Dent Oral Epidemiol. 2012;40:550-9.

54. Barros VM, Seraidarian PI, Cortes MI, Paula LV. The impact of orofacial pain on the quality of life of patients with temporomandibular disorder. J Orofac Pain. 2009;23:28-37.

55. Schierz O, John MT, Reissmann DR, Mehrstedt M, Szentpetery A. Comparison of perceived oral health in patients with temporomandibular disorders and dental anxiety using oral health-related quality of life profiles. Qual Life Res. 2008;17:857-66.

56. Edman K, Holmlund A, Nordstrom B, Ohrn K. Attitudes to dental care, Sweden 2003-2013, and clinical correlates of oral health-related quality of life in 2013. Int J Dent Hyg. 2018;16:257-66.

57. Vargas-Ferreira F, Piovesan C, Praetzel JR, Mendes FM, Allison PJ, Ardenghi TM. Tooth erosion with low severity does not impact child oral healthrelated quality of life. Caries Res. 2010;44:531-9.

58. Papagianni CE, van der Meulen MJ, Naeije M, Lobbezoo F. Oral healthrelated quality of life in patients with tooth wear. J Oral Rehabil. 2013:40:185-90

\section{Publisher's Note}

Springer Nature remains neutral with regard to jurisdictional claims in published maps and institutional affiliations.

Ready to submit your research? Choose BMC and benefit from:

- fast, convenient online submission

- thorough peer review by experienced researchers in your field

- rapid publication on acceptance

- support for research data, including large and complex data types

- gold Open Access which fosters wider collaboration and increased citations

- maximum visibility for your research: over $100 \mathrm{M}$ website views per year

At $\mathrm{BMC}$, research is always in progress.

Learn more biomedcentral.com/submissions 